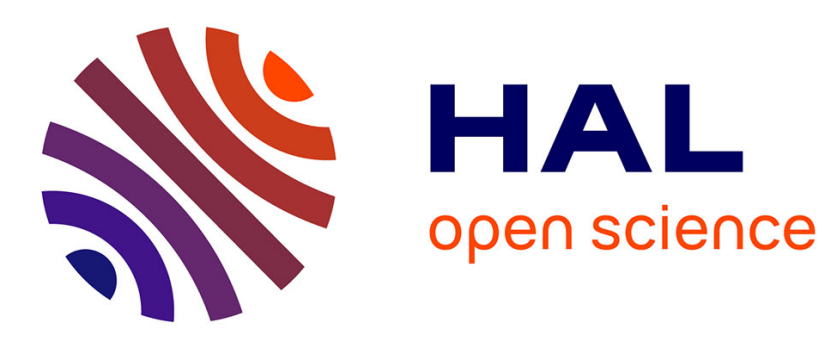

\title{
Total Productive Maintenance (TPM) as a Business Strategy in Manufacturing Small and Medium Enterprises in Nigeria
}

\author{
C Ihueze Chukwutoo, C Igbokwe Nkemakonam
}

\section{- To cite this version:}

C Ihueze Chukwutoo, C Igbokwe Nkemakonam. Total Productive Maintenance (TPM) as a Business Strategy in Manufacturing Small and Medium Enterprises in Nigeria. Advances in Research on Teaching, 2018, 15, pp.1 - 9. 10.9734/air/2018/41330 . hal-03384467

\author{
HAL Id: hal-03384467 \\ https://hal.science/hal-03384467
}

Submitted on 19 Oct 2021

HAL is a multi-disciplinary open access archive for the deposit and dissemination of scientific research documents, whether they are published or not. The documents may come from teaching and research institutions in France or abroad, or from public or private research centers.
L'archive ouverte pluridisciplinaire $\mathbf{H A L}$, est destinée au dépôt et à la diffusion de documents scientifiques de niveau recherche, publiés ou non, émanant des établissements d'enseignement et de recherche français ou étrangers, des laboratoires publics ou privés. 


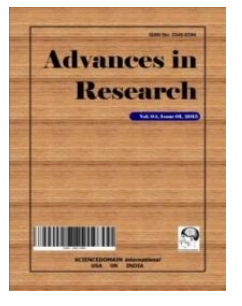

\title{
Advances in Research
}

15(5): 1-9, 2018; Article no.AIR.41330

ISSN: 2348-0394, NLM ID: 101666096

\section{Total Productive Maintenance (TPM) as a Business Strategy in Manufacturing Small and Medium Enterprises in Nigeria}

\author{
C. Ihueze Chukwutoo ${ }^{1}$ and C. Igbokwe Nkemakonam ${ }^{1 *}$ \\ ${ }^{1}$ Department of Industrial and Production Engineering, Nnamdi Azikiwe University, Awka, Nigeria.
}

Authors' contributions

This work was carried out in collaboration between both authors. Author CIN designed the study, performed the statistical analysis, wrote the protocol and first draft of the manuscript. Authors CIC and

CIN managed the analyses of the study. Author CIN managed the literature searches. Both authors read and approved the final manuscript.

Article Information

DOI: $10.9734 / A I R / 2018 / 41330$ Editor(s):

(1) Dr. Simone Domenico Scagnelli, Department of Management, University of Torino, Italy. Reviewers:

(1) Elżbieta Szczepankiewicz, Poznan University of Economics and Business, Poland. (2) Sergey N. Polbitsyn, Ural Federal University, Russia. (3) Shih-Wei Wu, National Taipei University of Technology, Taiwan. Complete Peer review History: http://www.sciencedomain.org/review-history/25308

Original Research Article

Received $9^{\text {th }}$ April 2018

Accepted $22^{\text {nd }}$ June 2018

Published 28 ${ }^{\text {th }}$ June 2018

\section{ABSTRACT}

The goal of this study is to provide insights into total productive maintenance implementation as a business strategy in a manufacturing SME in Nigeria that has had success in implementing it. A combination of a qualitative and quantitative investigation was used for this study, which comprises of literature review, questionnaire survey, comprehensive interviews, and direct observation. In order to achieve competitive advantage in the manufacturing sector, implementing TPM is an effective business strategy, thus this study reviewed Total Productive Maintenance (TPM) implementation as a business strategy in a manufacturing SME in Nigeria, and it was found that Total Productive Maintenance (TPM) not only improved overall equipment effectiveness (OEE) but also created a safe working environment enabling workers to achieve goals working as a team, thus increasing morale in the enterprise.

\footnotetext{
${ }^{*}$ Corresponding author: E-mail: nkemakonam.igbokwe@gmail.com, sultan0032001@gmail.com;
} 
Keywords: Total productive maintenance (TPM); manufacturing SMEs; overall equipment effectiveness (OEE); business strategy; competitive advantage.

\section{INTRODUCTION}

To achieve competitive advantage in manufacturing sectors, Small and medium enterprises (hereinafter SMEs) are being forced to look inwards at various production functions and business processes. This is done to optimise manufacturing processes, eliminate equipment breakdowns and increase efficiency through economies of scale paying attention to quality and process improvements. According to [1], manufacturing systems often operate at less than full capacity potential equipment breakdown thus leading production wastes and losses. And as a result, productivity will be low, and the cost of producing goods and services will be high. To combat these losses, the concept of total productive maintenance (hereinafter TPM) is one of the several methodologies used to eliminate losses in a manufacturing process. This is further supported by [2]. A study by [3] further concluded that there is a positive correlation between implementing TPM and business performance thus necessitating the need for TPM to be an integrated effort of the entire manufacturing enterprise.

Total productive maintenance a methodology developed by the Japanese in 1971 is a philosophy based on productivity maintenance and innovative in approach ensuring that there is no equipment and production breakdown, optimizes equipment effectiveness, eliminates defects in a production system and promotes autonomous maintenance through the establishment of a thorough system of preventive maintenance for equipment life span. According to [4], the objective of every TPM implementation is to advance productivity and quality along with better employee self-esteem and job satisfaction, ensuring joint responsibility between supervisors, operators and maintenance workers, and not simply to keep machines running smoothly, but also to extend and optimize their performance overall.

Therefore TPM as a whole places emphasis on [5]:

- Maximizing overall equipment effectiveness.

- Establishing a planned system of Preventive Maintenance (PM) for the equipment's life span.

- Involving all employees from top management to shop floor workers.

- Empowering employees to initiate corrective activities.

TPM is successfully implemented through its unique eight pillar methodology as shown in figure one, paving the way for excellent planning, organising, monitoring and controlling manufacturing practices.

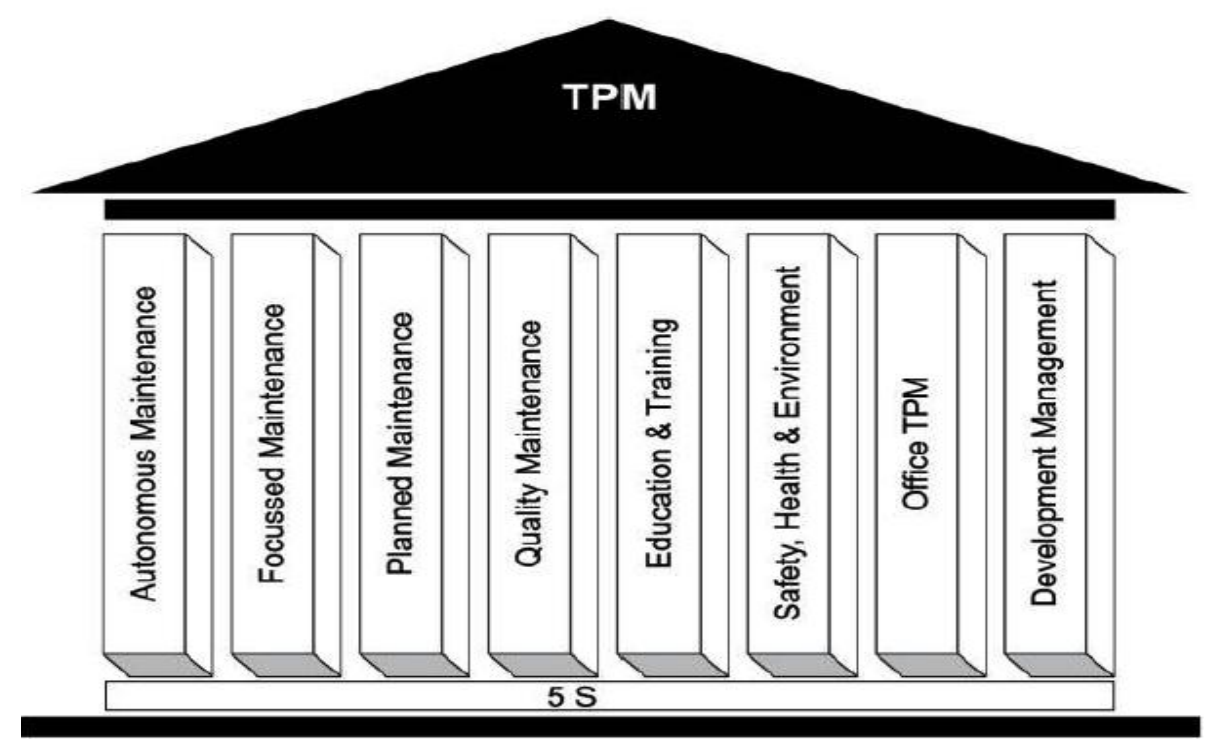

Fig. 1. The eight pillars of Total Productive Maintenance [6] 
Because it is the foundation on which TPM is built on, implementing TPM starts first with $5 S$. $5 S$ according to [7] is a methodical process of housekeeping to achieve a peaceful environment in the workplace involving the employees with a commitment to implement and practice housekeeping sincerely. The philosophy starts with the cleaning and the arranging of the working environment and when implemented properly leads to a reduction of defective products, lead time, unhappy customers, disheartened workers, and dwindling returns.

Tables 1 and 2 outlines the key activities for $5 \mathrm{~S}$ and TPM implementation in a working environment.

Table 1. 5 S activities

\begin{tabular}{|c|c|}
\hline Japanese term (English Term) & Characteristics \\
\hline \multirow[t]{2}{*}{ Seiri (Sort/Clear) } & Sort out all unnecessary items from the \\
\hline & Working environment and get rid of them \\
\hline Seiton (Set in order/Configure) & $\begin{array}{l}\text { Arrange all necessary items in good order so that they can } \\
\text { be easily picked up for use }\end{array}$ \\
\hline Seisio (Shine/Clean and check) & $\begin{array}{l}\text { Clean the workplace completely to make it free from dust, } \\
\text { dirt and untidiness }\end{array}$ \\
\hline Seiketsu (Standardize/Conformity) & $\begin{array}{l}\text { Maintain a high standard of housekeeping and workplace } \\
\text { organisation }\end{array}$ \\
\hline $\begin{array}{l}\text { Shitsuke (Sustain/Custom and } \\
\text { practice) }\end{array}$ & $\begin{array}{l}\text { Train and motivate people to follow good housekeeping } \\
\text { disciplines autonomously }\end{array}$ \\
\hline
\end{tabular}

Table 2. Description of the eight pillars of TPM

\begin{tabular}{cll}
\hline Pillars & Description \\
\hline $1 . \quad$ Autonomous maintenance & $\begin{array}{l}\text { Targeted through towards developing operators that are } \\
\text { able to take care of small maintenance tasks, thus } \\
\text { freeing up the skilled maintenance people to spend time } \\
\text { on more value-added activity and technical repairs. }\end{array}$ \\
\hline 2. Focused maintenance & $\begin{array}{l}\text { Through which focused maintenance activities } \\
\text { maximize the overall effectiveness of equipment and } \\
\text { processes by the elimination of wastes/losses and } \\
\text { continuous improvement. }\end{array}$ \\
\hline 3. & Establishes and maintains optimal conditions through
\end{tabular}

3. Planned maintenance Establishes and maintains optimal conditions through planned maintenance, achieved through daily, weekly and monthly assessments to monitor defects and implement improvement programmes.

4. Quality maintenance Ensures customer satisfaction through zero defects by placing emphasis on eliminating non conformance cost.

5. Education \& Training Aims at upgrading the skills and morale of the operators and workers with the goal to create experts in the working environment.

6. Safety Health \& Environment Aims to create a safe working environment with the goal of achieving zero accidents etc.

7. Office TPM

Follows the first four pillars of TPM to improve productivity and efficiency of organizational activities through the automation of essential processes

8. Development Management Aims to reduce overall the cost of maintenance in the working environment, reducing Mean Time to Repair (MTTR) and improving Mean Time Between Failure (MTBF) 


\subsection{Small and Medium Enterprise (SME)}

The term SME stands for small and medium enterprise; some countries have further extended the definition to be SMME, which stands for small, medium and micro enterprise [8].

In Nigeria, the National Bureau of Statistics describes a small and medium enterprise as a separate and distinct entity including cooperative enterprises and non-governmental organizations managed by one owner or more including its branches or subsidiaries. Table 3 illustrates this description.

Manufacturing SMEs play an essential function in global economies by creating employment and thus reducing poverty. This is further supported by the economic report by the Small and medium Enterprises development Agency of Nigeria (SMEDAN) and National Bureau of Statistics (NBS) for 2014, stating SMEs contribution to Gross Domestic Product in Nigeria in nominal terms stood at $55.55 \%$, as seen in Table 4.

According to [2], many industries in Nigeria function effectively for less than $50 \%$. Part of the issues is usually caused by excessive downtime, supply failures for input resources, and low spare-capacity to cope with sudden high demands. Manufacturing SME's in Nigeria are not exempted from this issue and unfortunately, the idea of implementing TPM to effectively combat excessive downtime has not been adopted by a meaningful number of manufacturing SMEs. TPM as a tool for process improvement is a tool used to enhance productivity and efficiency, but [10] reports that Manufacturing SMEs are not certain about the cost of implementing such tool hence have no idea about the tangible benefits obtainable. This puts Manufacturing SMEs in Nigeria in a precarious situation as they must be reactive to the current economic situation in order to stay in business and make profits.

On the other hand, most manufacturing SMEs in Nigeria lack access to adequate data necessary for decision making hence leading to disastrous decisions being taken by the owner/manager or the production manager [11]. Thus this study aims to provide insights into total productive maintenance implementation as a business strategy in a manufacturing SME that has had success implementing it.

Table 3. Definition of SMEs in Nigeria

\begin{tabular}{llll}
\hline S/N & Size category & Employment & Assets (=N= Million) (excl. land and buildings) \\
\hline 1 & Micro enterprises & Less than 10 & Less than 5 \\
2 & Small enterprises & 10 to 49 & 5 to less than 50 \\
3 & Medium enterprises & 50 to 199 & 50 to less than 500 \\
\hline
\end{tabular}

Table 4. SMEs contribution to national GDP, 2014 [9]

\begin{tabular}{lllll}
\hline Activity & Sector & Micro & Small & Medium \\
\hline Agriculture & 86.53 & 6.53 & 3.95 & 97.01 \\
Mining and quarrying & 0.28 & 0.39 & 3.60 & 4.27 \\
Manufacturing & 14.28 & $\mathbf{2 1 . 2 7}$ & $\mathbf{1 9 . 9 8}$ & $\mathbf{5 5 . 5 3}$ \\
Water supply, sewage, waste management & 25.44 & 6.63 & 2.51 & 34.57 \\
and remediation & & & & \\
Construction & 0.52 & 2.02 & 7.68 & 10.22 \\
Trade & 36.34 & 14.39 & 8.68 & 59.41 \\
Accommodation and food services & 4.23 & 27.98 & 13.68 & 45.90 \\
Transportation and storage & 50.73 & 5.60 & 12.03 & 68.36 \\
Information and communication & 0.00 & 2.38 & 9.57 & 11.95 \\
Arts, entertainment and recreation & 47.35 & 28.20 & 22.26 & 97.82 \\
Finance and insurance & 1.05 & 1.39 & 3.69 & 6.13 \\
Real estate & 31.00 & 13.25 & 11.29 & 55.55 \\
Profession, scientific and technical services & 13.25 & 2.08 & 5.28 & 20.61 \\
Administrative \& support services & 8.55 & 15.20 & 65.76 & 89.51 \\
Education & 2.09 & 14.69 & 24.48 & 41.26 \\
Human health and social services & 18.24 & 20.06 & 20.96 & 59.25 \\
Other services & 80.76 & 17.01 & 2.23 & 100.00 \\
\hline
\end{tabular}




\section{MATERIALS AND METHODS}

An empirical study was carried out in order to analyse and evaluate the effectiveness of implementing TPM in such manufacturing enterprises.

The study obtained historical maintenance records for 7 months prior to the implementation of TPM and carried out on the spot observation for a total of 4200 hours of machine time after TPM implementation this was done. Direct observation was carried out on the machine via method study in other find out the current efficiency, compare with the obtained data and to analyze the area associated with the problem which causes the low OEE.

It was conducted in an enterprise manufacturing foam mattress and began implementing TPM in 2013 as a result of the need to reduce downtime losses and production costs, and reactive maintenance cost that accounted for $23 \%$ of its manufacturing cost. This methodology was implemented in stages outlines as follows (See Table 5):

Stage 1: Introductory stage: in which the owner/manager and the production manager indicated the need to implement TPM. TPM targets and objectives were also identified (Table 5).

Stage 2: Preparatory stage: Staff Training and the preparation of TPM implementation plan

Stage 3: Execution stage: Execution of TPM to improve efficiency, using the eight pillars of TPM.

\section{RESULTS}

Overall equipment effectiveness (OEE) takes into account, the availability rate, quality rate and performance rate and is represented as:

OEE $=$

Availability x Performance Rate x Quality Rate (1)

Where availability accounts for losses as a result of equipment failure, setup and adjustment and is calculated as the ratio of operating time to loading time and is calculated as follows:

Availability $=\frac{\text { Plannedruntime }- \text { Planneddowntime }}{\text { Plannedruntime }} \times 100$

And performance rate accounting for losses due to idle time and minor stoppages and is calculated as ratio of net operating time to operating time and is calculated as follows:

Performance rate $=\frac{\text { Total Actual amount of product }}{\text { Target amount of product }} \times 100$

Quality rate factors in the defects in process and reduced yield and is defined as ratio of valuable operating time to net operating time and is calculated as follows:

Quality rate $=\frac{\text { Processed Quantity }- \text { defective quantity }}{\text { Processed quantity }} \times 100$

In summary, the generally accepted world-class goals for each factor used to compare to the overall equipment effectiveness (OEE) of a firm is shown in Table 6.

Table 5. TPM targets and objectives (Manufacturing SME)

\begin{tabular}{ll}
\hline \multicolumn{1}{c}{ TPM targets and objectives } & (Manufacturing SME) \\
\hline Internal targets & External targets \\
\hline Reduction in downtime losses and production cost & Increase in quality output \\
Eliminate reactive maintenance & Meeting customer demands Just-in-time \\
\hline Target goal \\
\hline To achieve zero downtime losses through preventive maintenance \\
\hline Target objectives \\
\hline 1. Reduce equipment and power failure \\
2. Eliminate or reduce waiting time for instructions and materials \\
3. Maximise effective utilization of resources \\
4. Development staffs skill through skills acquisition and training \\
5. Improve competitiveness, quality, performance and cost. \\
6. Increase the reaction time to customer needs Just-in-time \\
\hline
\end{tabular}


Table 6. World class goals for OEE [12]

\begin{tabular}{ll}
\hline OEE factor & World class rate (\%) \\
\hline Availability & $>90.0 \%$ \\
Performance Rate & $>95 \%$ \\
Quality Rate & $>99 \%$ \\
OEE & $85 \%$ \\
\hline
\end{tabular}

The manufacturing process for the production of a foam mattress in company $A$ was observed and can be broken down into the following process below in Fig. 1.

From the Table 3 , it was observed that the availability figures were found to be comparatively lower than the world average standard for availability (see Fig. 2). In order to identify the causes behind these findings, detailed downtime analysis was carried out.
From data collected during the interviews and direct observation of the manufacturing process, factors causing the downtime losses before TPM implementation were identified and a Pareto analysis of the downtime losses showed that equipment breakdown was the major cause. Pareto analysis helps in identifying the factors that are majorly responsible for production system failure (see Table 8 and Fig. 3).

\section{DISCUSSION}

With the major cause of downtime indentified, and by implementing TPM, a systematic form of planned preventive maintenance was put in place that establishes and maintains optimal conditions through routine maintenance of equipments thus ensuring that downtime losses was reduced.

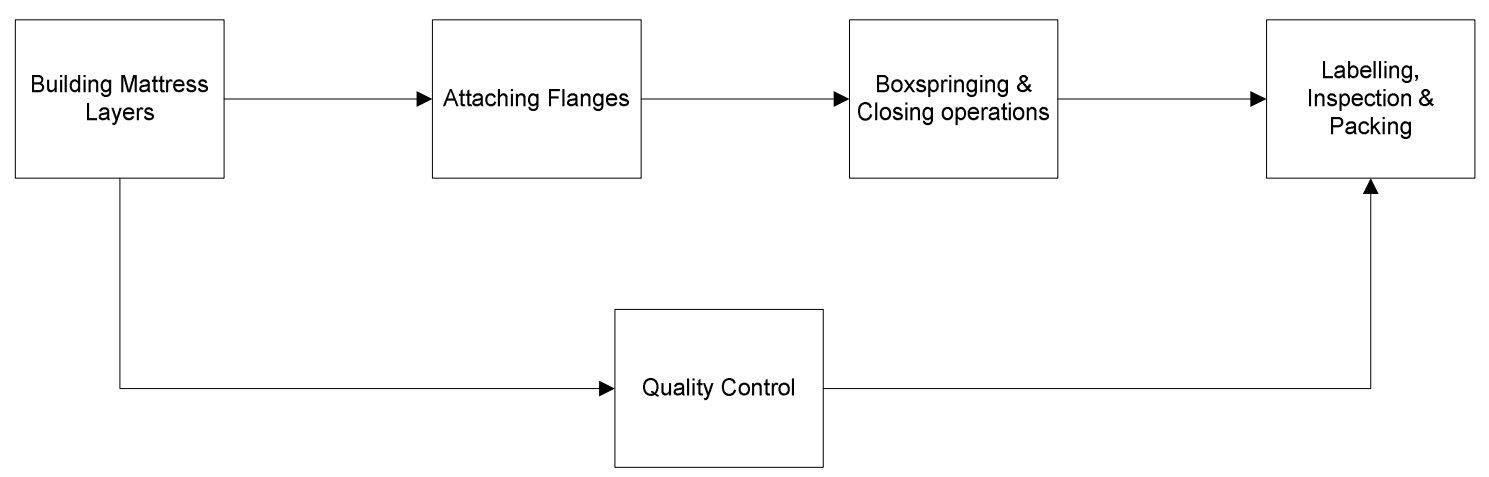

Fig. 1. Manufacturing process foam mattress

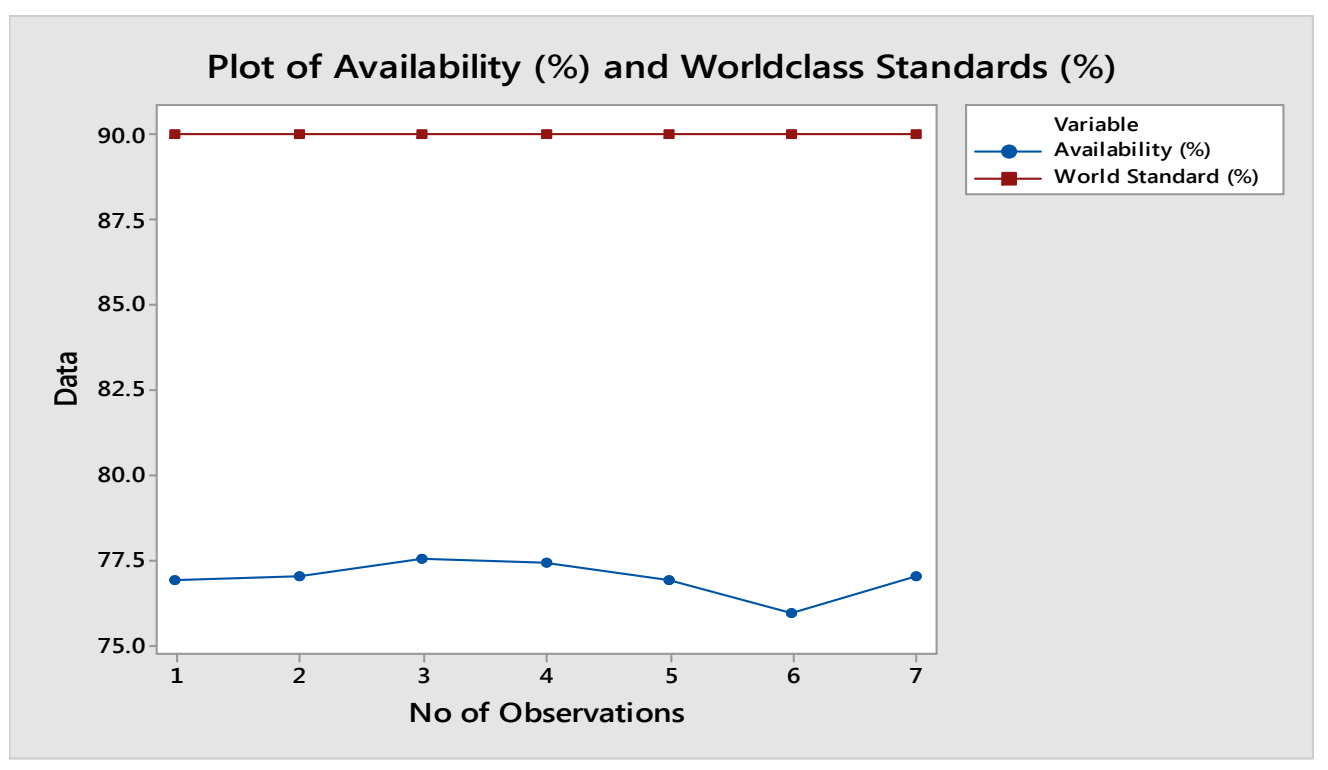

Fig. 2. Measured availability in comparison with world standards 
Table 7. Summary of OEE measurements before TPM Implementation

\begin{tabular}{lllll}
\hline No of Observations & Availability (\%) & Performance (\%) & Quality (\%) & OEE (\%) \\
\hline 1 & 76.9 & 91.7 & 95.5 & 67.3 \\
2 & 77.0 & 92.0 & 96.8 & 68.5 \\
3 & 77.5 & 92.2 & 95.0 & 67.8 \\
4 & 77.4 & 91.8 & 95.1 & 67.5 \\
5 & 76.9 & 91.6 & 94.9 & 66.8 \\
6 & 75.9 & 92.0 & 96.3 & 67.2 \\
7 & 77.0 & 92.0 & 96.2 & 68.1 \\
\hline
\end{tabular}

Table 8. Downtime losses

\begin{tabular}{llll}
\hline Downtime factor & Downtime factor (Mins) & Percentage & $\begin{array}{l}\text { Cumulative } \\
\text { Percentage }\end{array}$ \\
\hline Equipment failure & & $\mathbf{4 6 . 1 5}$ & $\mathbf{4 6 . 1 5}$ \\
Power Failure & $\mathbf{3 0 0}$ & 23.07 & 69.22 \\
Scheduled Maintenance & 150 & 15.38 & 84.6 \\
Waiting for materials and instructions & 100 & 6.15 & 90.75 \\
Job meetings and training & 40 & 6.15 & 96.9 \\
Others & 40 & 3.07 & 100 \\
\hline
\end{tabular}

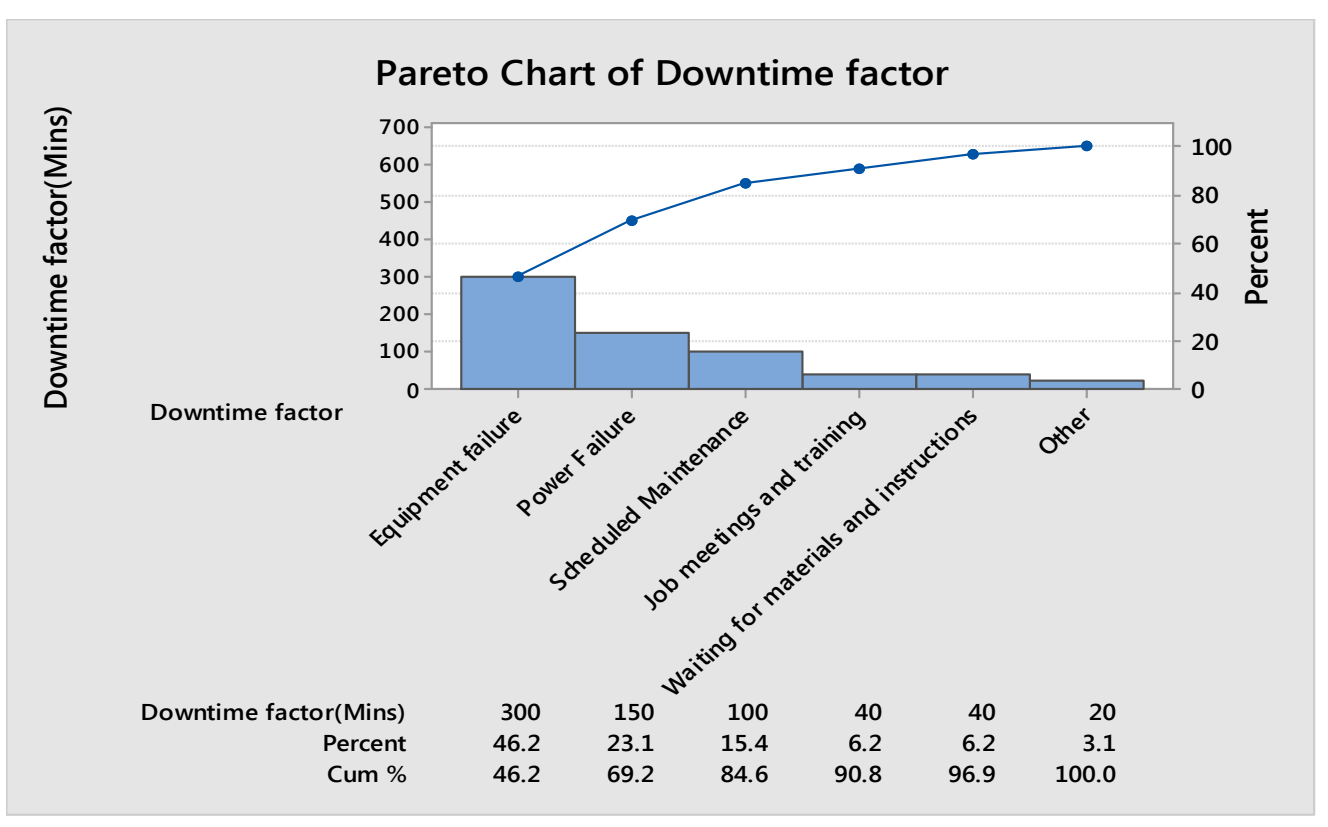

Fig. 3. Downtime analysis Pareto chart

From Table 9, it can be seen that after TPM was implemented, overall equipment effectiveness (OEE) improved tremendously as seen in figure 4 , thus proving to be very effective business strategy for improving competitive advantage and customer satisfaction for the end user.

Implementing TPM at the manufacturing enterprise also enable the enterprise to reduce the need for reactive maintenance hence achieving reduced manufacturing cost, reduced customer complaints and improved its product sales. This is very important as it is necessary for manufacturing firms to achieve full productive capacity. Indirectly, implementing TPM created a safe working environment enabling workers to achieve goals working as a team, thus increasing morale in the enterprise. 
Table 9. TPM effectiveness analysis and benchmarks

\begin{tabular}{llll}
\hline S/No & Category & Before TPM Implementation & After TPM Implementation \\
\hline 1 & Total Time & 4200 & 4200 \\
2 & Downtime & 650 & 600 \\
3 & Planned Runtime & 3550 & 3550 \\
4 & Runtime losses & 820 & 570 \\
5 & Operating time & 2730 & 2980 \\
6 & Total Units produced & 200 & 233 \\
7 & Production rate(Units/min) & 0.80 & 0.80 \\
8 & Target Unit & 218 & 238 \\
9 & Defected units & 9 & 3 \\
10 & Availability (A) & $76.9 \%$ & $83.9 \%$ \\
11 & Performance rate (P) & $91.7 \%$ & $97.8 \%$ \\
12 & Quality rate (Q) & $95.5 \%$ & $98.7 \%$ \\
13 & QEE & $67.41 \%$ & $80.98 \%$ \\
\hline
\end{tabular}

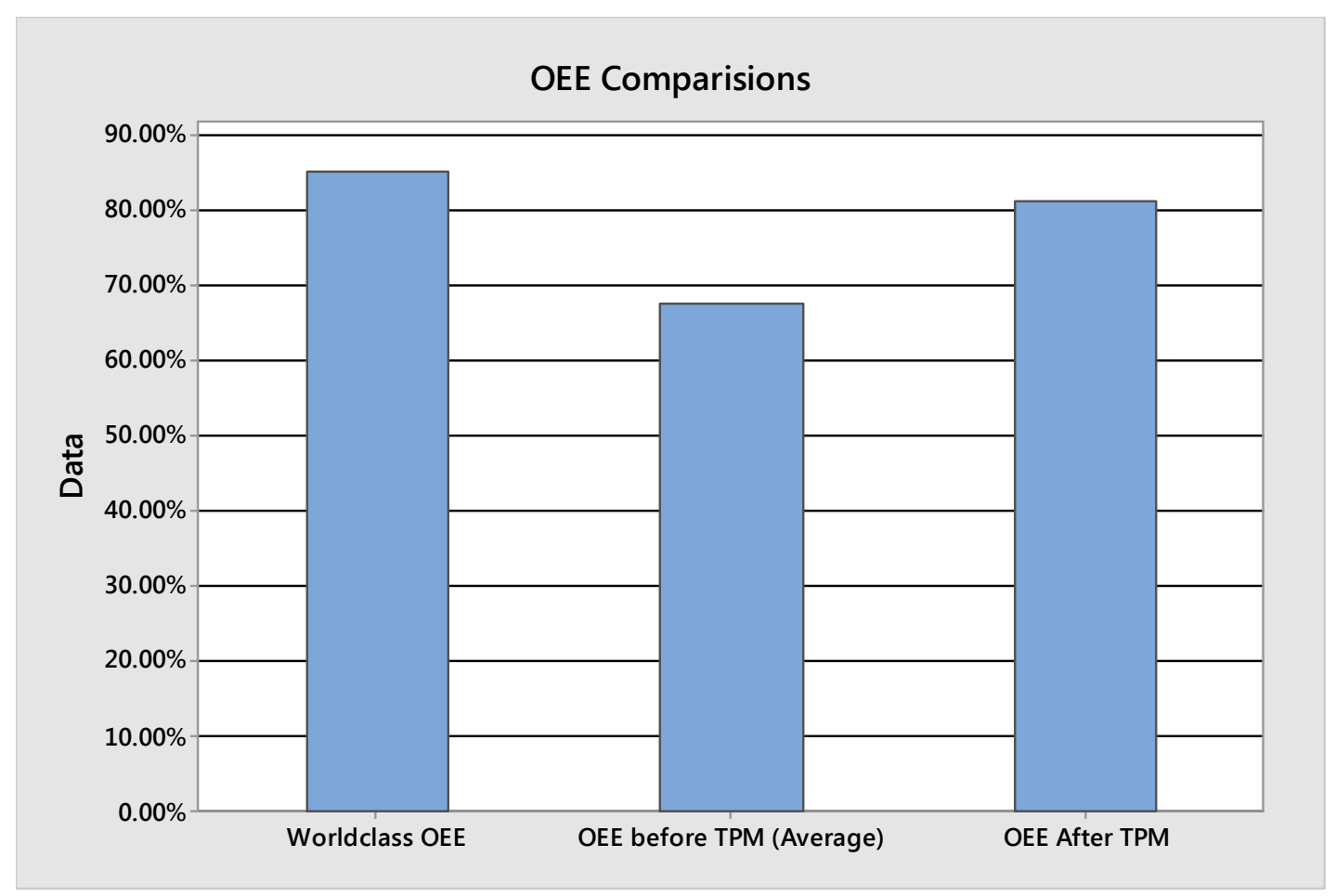

Fig. 4. OEE Comparisons

It was also observed from the survey that implementing TPM wasn't easy initially due to the need to training staffs to acquire TPM skills thereby increasing manpower cost and the amount of time required in doing so, thus requiring long-term planning. This is further supported by [13] and [14], In which they stated that in order to combat these factors that contribute to the failure of TPM implementation in manufacturing SMEs, it is necessary to maintain the synergy and willingness of the staffs and the owner/manager involved in order to make TPM implementation continuous and successful.

\section{CONCLUSION}

In order to achieve competitive advantage in the manufacturing sector, implementing TPM is the key. It has been proven to be efficient and effective in improving performance efficiency and 
quality thus improving revenue from product sales.

Therefore the following can be adopted from this study:

- Implementing TPM can enable a manufacturing SME to reduce production losses and achieve competitive advantage.

- An appropriate TPM implementation plan has to be in place considering the manufacturing SME's values, beliefs and mission.

The study also found that TPM not only improves overall equipment effectiveness (OEE) but also created a safe working environment enabling workers to achieve goals working as a team, thus increasing morale in the enterprise, hence making it a tool to improve workers productivity.

\section{COMPETING INTERESTS}

Authors have declared that no competing interests exist.

\section{REFERENCES}

1. Wang FK, Lee W. Learning curve analysis in total productive maintenance. The International Journal of Management Sciences. 2001;29:491-499.

2. Eti M, Ogaji S, Probert S. Implementing total productive maintenance in Nigerian manufacturing industries. Applied Energy. 2004;79:385-401.

3. Brah S, Chong W. Relationship between total productive maintenance and performance. International Journal of Production Research. 2004;42(12):23832401.

4. Singh R, Gohil AM, Shah D, Desa S. Total productive maintenance (TPM) implementation in a machine shop: A case study. Procedia Engineering. 2013;51:592 -599 .

5. Thomas M. Complimentarity of TPM and TQM: The Indian Experience. Sevilla; 2000.

6. Ahuja IPS, Kumar P. A case study of total productive maintenance implementation at precision tube mills. Journal of Quality in Maintenance Engineering. 2009;15(3):241258.

7. Amit Kumar Gupta, Garg DRK. OEE improvement by TPM implementation: A case study. International Journal of IT, Engineering and Applied Sciences Research (IJIEASR). 2012;1(1):115-125.

8. Monks PG. Sustainable growth of Sme's, Port Elizabeth; 2010.

9. Smedan and National Bureau of Statistics Collaborative Survey: Selective Findings, Abuja: Smedan; 2014.

10. Achanga P, Shehab E, Roy R, Nelder AG. Critical success factors for lean implementation within SMEs. Journal of Manufacturing Technology Management. 2006;17(4):460-471.

11. Tom EE. Glory B, Alfred UJ. An appraisal of Nigeria's micro, small and medium enterprises. International Journal of Small Business and Entrepreneurship Research. 2016;4(4):1-15.

12. Kailas C. Modern approach to overall equipment effectiveness (OEE), Seminar Report; 2009.

13. Marcelo Rodrigues, Hatakeyama K. Analysis of the fall of TPM in companies. Journal of Materials Processing Technology. 2006;179:276-279.

14. Bamber C, Sharp J, Hides M. Factors affecting successful implementation of total productive maintenance. Journal of Quality in Maintenance Engineering. 1999;5(3): 162-181.

(c) 2018 Chukwutoo and Nkemakonam; This is an Open Access article distributed under the terms of the Creative Commons Attribution License (http://creativecommons.org/licenses/by/4.0), which permits unrestricted use, distribution, and reproduction in any medium, provided the original work is properly cited.

Peer-review history:

The peer review history for this paper can be accessed here: http://www.sciencedomain.org/review-history/25308 